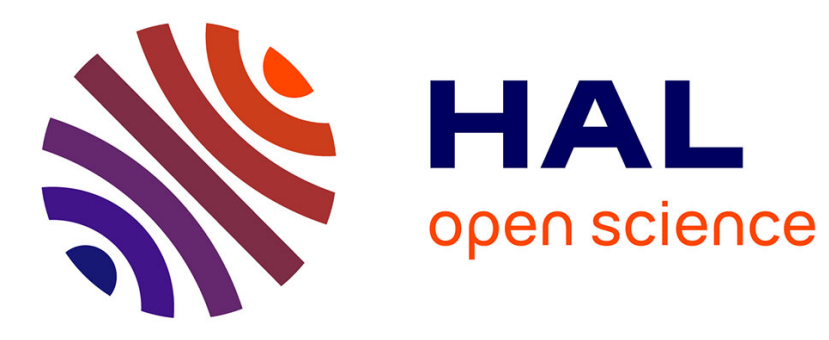

\title{
Murine Models for Leptospirosis Kidney Disease Catherine Werts
}

\section{To cite this version:}

Catherine Werts. Murine Models for Leptospirosis Kidney Disease. Yang C-W, Pan M-J, Yan HY. Leptospirosis and the Kidney, 7, Karger, pp.65-75, 2019, Translational Research in Biomedicine, 10.1159/000500388. pasteur-02337989

\section{HAL Id: pasteur-02337989 \\ https://hal-pasteur.archives-ouvertes.fr/pasteur-02337989}

Submitted on 29 Oct 2019

HAL is a multi-disciplinary open access archive for the deposit and dissemination of scientific research documents, whether they are published or not. The documents may come from teaching and research institutions in France or abroad, or from public or private research centers.
L'archive ouverte pluridisciplinaire HAL, est destinée au dépôt et à la diffusion de documents scientifiques de niveau recherche, publiés ou non, émanant des établissements d'enseignement et de recherche français ou étrangers, des laboratoires publics ou privés.

\section{(ㅇ)(1) $\$$}

Distributed under a Creative Commons Attribution - NonCommercial - NoDerivatives| 4.0 


\title{
Murine Models for Leptospirosis Kidney Disease
}

\section{Catherine Werts}

Institut Pasteur, Unité Biologie et Génétique de la Paroi Bactérienne, Groupe Immunité Innée et Leptospires, Paris, France

\begin{abstract}
Leptospirosis is a worldwide neglected zoonosis caused by the bacterium Leptospira interrogans. These spirochetes are widespread pathogens able to infect virtually all vertebrates. They may colonize the kidneys of their hosts, as in rodents, which are a common, asymptomatic reservoir of the disease. Infected animals excrete the bacteria in their urine, contaminating the environment. Although most leptospirosis cases are mild or unnoticed, humans and some animals may suffer from acute, severe leptospirosis with multi-organ failure and potentially chronic kidney disease in survivors. The hamster model, reproducing the severe human disease, has been traditionally used to study the pathophysiology of the acute disease and the virulence factors of leptospires. Nevertheless, the mouse model, which is rather resistant to the acute disease, is a valuable model to study chronic renal colonization and subsequent mild fibrosis. Moreover, the use of transgenic mice has given important insight about the host immune factors required to control the acute disease, such as B cells producing immunoglobulins and the pattern recognition receptor Toll-like receptor 4 . In this chapter, we will summarize studies in mice that contributed to a better understanding of leptospirosis kidney disease at the acute and chronic phases.
\end{abstract}

\section{Introduction}

Leptospirosis is caused by pathogenic Leptospira species. Depending on the host species, and the infecting serovars, leptospirosis presents different subclinical and clinical forms and a wide array of symptoms (fever, headaches, uveitis, hemorrhaging, jaundice, meningitis, pulmonary, liver and renal failure, abortions, etc.) [1]. The human acute disease is often considered as a peculiar form, different from the chronic, renal colonization affect- 
ing reservoir animals and cattle. However, recent studies showed that human populations living in endemic area of leptospirosis could also asymptomatically excrete leptospires in their urine for a long time [2]. As a consequence, it was recently proposed that leptospirosis, in most cases asymptomatic, may be an overlooked cause of chronic kidney disease $[3,4]$.

Mice were not considered to be good models of leptospirosis since infections are mostly asymptomatic. However, we recently highlighted that the experimental intraperitoneal infection of mice with pathogenic Leptospira interrogans leads to a biphasic disease, with an acute phase corresponding to the systematic dissemination and replication of bacteria in blood, followed by the disappearance of bacteria from the circulation and reappearance of bacteria restricted to the kidney [5]. This renal colonization was similar to the colonization observed in rats, the usual model to study chronic leptospirosis [6]. Interestingly, infection with high doses of the virulent L. interrogans serovar Manilae L495 strain killed C57BL6/J mice from septicemia in the first week postinfection, reproducing the acute form of the disease [5]. Finally, recent studies showed that hamsters that survive experimental infection also present chronic kidney colonization [7]. Therefore, acute and chronic leptospiroses are the 2 facets of a biphasic disease. According to the fitness of their immune system, the host may suffer from asymptomatic, mild, or severe acute forms, with or without subsequent renal colonization. The purpose of this chapter is to sum up the findings obtained using mouse models that highlight (1) the pathophysiology of acute and chronic leptospirosis focusing on the kidney and (2) the host immune determinants known to control leptospires and avoid an acute severe disease.

\section{Pathophysiology of Acute and Chronic Leptospirosis Focusing on the Kidney}

Leptospires are shed in the environment by animals carrying leptospires in their kidneys and excreting the bacteria in urine. Pathogenic leptospires enter the body of their hosts through mucosa or damaged skin, thanks to their motility [8].

The habitual mouse models of leptospirosis use the intraperitoneal route to inoculate the bacteria since this allows for a precise monitoring of the infectious dose and provides reproducible results, even it does not precisely mimic the natural route of infection. At the peak of the acute phase (3-4 days post-intraperitoneal injection), when leptospires disseminate and replicate in blood, the bacteria are present in all irrigated organs, such as lungs, liver, and kidneys [5, 9]. The L. interrogans Fiocruz, Verdun, and Manilae strains have been observed in the renal interstitium by immunolabeling, using antibodies against LipL32, the major lipoprotein of L. interrogans, and the corresponding bacterial loads are measured by quantitative PCR [5, 9]. Interstitial nephritis is barely observed in resistant mice but is more prominent in susceptible mice infected with high doses of $L$. interrogans (see paragraph 2 and Fig. 1 for the definition of sensitive and resistant mice). Interstitial nodular infiltrates are composed of mostly T cells and monocytic cells [9]. Interestingly, very few neutrophils were found in the kidneys of mice upon infection with the L. inter- 


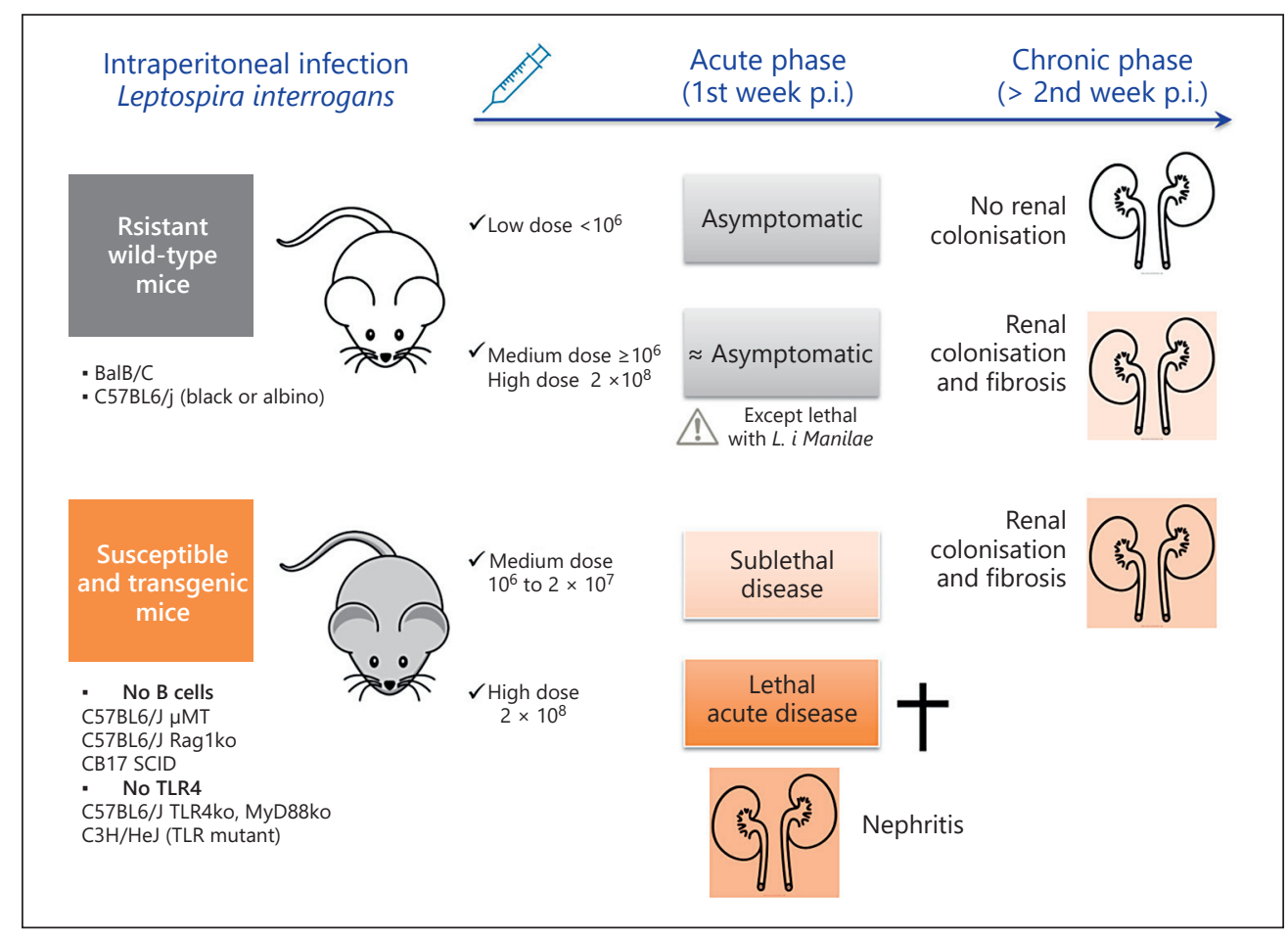

Fig. 1. Scheme of the outcome of intraperitoneal infection of mice with Leptospira interrogans at the acute and chronic phases, depending on the genotype of sensitive or resistant mice and the dose of the inoculum.

rogans Fiocruz, Manilae, or Lai strains $[10,11]$. This was unexpected considering the marked upregulation of several cytokines (interleukin-1 $\beta$ [IL-1 $\beta]$, tumor necrosis factor [TNF] alpha, IL-6,) and chemokines [RANTES, KC]) measured in kidneys of infected mice $[9,11]$, which should have led to polymorphonuclear leukocytes recruitment, as has been observed in the hamster model [7]. Depending on the dose and strains of leptospires used, sensitive and resistant mice may die from acute leptospirosis in the first week postinfection, presenting septicemia and multi-organ failure. The symptoms associated with lethality are a ruffled fur, closed eyes, dark yellow urine revealing the icterus, pronounced prostration, and a weight loss of more than $15 \%$ of the initial weight at day 2 or 3 postinfection. With lethal doses, at day 3 postinfection, besides high levels of ASAT and ALAT showing liver impairment, mice display consistently high levels of blood urea nitrogen and serum creatinine, evocative of renal failure [9]. Interestingly, from 3 to 4 days after sublethal infection, leptospires disappear from blood. We showed that leptospires were killed in blood [5], which correlated with a specific immunoglobulin (Ig)M response directed at the leptospiral lipopolysaccharide (LPS) that was partially protective and therefore may have participated in the control of leptospires [9].

Fifteen days post sublethal infection, WT mice are largely asymptomatic and have recovered their initial weight. We observed, tracking the bioluminescent bacteria by live 
imaging, that the renal colonization is proportional to the infectious dose and usually of the same magnitude as the peak measured in blood at day 3 or 4 postinfection. Below a threshold infective dose of $10^{6}$ bacteria per mouse, we rarely observed renal colonization [5] (Fig. 1), suggesting that the mouse blood defense, encompassing antimicrobial peptides, complement system, natural and specific IgM and phagocytes, was efficient to control a certain amount of bacteria. Therefore, it also suggests that above this dose, the mouse innate system is overwhelmed, which would allow the leptospires to disseminate through the circulation and settle in the kidney. Interestingly, using antibiotics, we showed that renal colonization occurs early, before day 3 post-intraperitoneal infection, potentially before the IgM response is effective.

In mouse kidneys, leptospires are observed in the cortex but not in the medulla or in the collecting duct. We did not observe leptospires within the glomerulus or in the distal tubules (unpublished observations). Leptospires are only settled in the proximal convoluted renal tubules. The reason for this is unknown, but we could speculate that more blood nutrients are available in the proximal region compared to other parts of the renal tubule. The renal colonization in resistant mice is not associated with elevated ASAT or blood urea nitrogen markers, and these mice are otherwise asymptomatic. The clinical features include multifocal nodular infiltrates of monocytes and Tymphocytes $[10,12]$ and, in addition, glomerular shrinking and tubular damage in sensitive mice [13]. Associated with a mild inflammation, upregulation of mRNA expression of RANTES, macrophage inflammatory protein $2, \mathrm{KC}, \mathrm{TNF}, \mathrm{IL}-1 \beta$, inducible nitric oxide $(\mathrm{NO})$ synthase (iNOS), the anti-inflammatory IL-10, IL-6, and interferon $\gamma($ IFN- $\gamma$ ) has been measured in the kidney tissue $[7,10,12,13]$. After $4-6$ weeks, the renal colonization reaches its maximum [5], and leptospires form aggregates that sometimes almost fill the lumen of tubules. Interestingly, the colonization is stable and asymptomatic over the entire life of WT mice (monitored for 23 months), without increase or disappearance of leptospires in kidneys ([5] and unpublished observations). On the contrary, sensitive Toll-like receptor (TLR)4 knock-out (ko) mice (see paragraph 2) died within the first-year post sublethal infection, with kidney disease and overwhelming renal colonization ([10] and unpublished data). Altogether, this suggests that in WT mice, leptospires replicate in tubules at the same pace as they are excreted in urine. Antibiotic treatment at the chronic phase with penicillin or ciprofloxacin (which effectively eliminate leptospires when administered early postinfection) led to a temporary slight reduction of the number of renal bacteria, but one week posttreatment, the level of leptospires in the kidneys was restored [5]. We also used azythromycin, a potent antibiotic treatment apparently able to clear most of the renal leptospires; however, after the treatment was stopped, the leptospires progressively reappeared, although with a clear reduction compared with the initial colonization. Another round of the same treatment resulted again in reduction of the number of leptospires [5]. Altogether, these data suggest that leptospires are rather resistant to antibiotic treatment and persistent when they are settled in the kidney (potentially because of biofilm formation). Once in the lumen of a tubule, the leptospires expand to fill this niche but do not exit the lumen to reach the renal interstitium or colonize new tubules, unless 
the innate response is not functional [5]. Besides protection against antibiotics, the localization of leptospires inside the lumen of the tubule would protect them against the efficient antibody-mediated killing. Indeed, serum of WT mice immunized for 20 days with L. interrogans has been shown efficient to rescue sensitive mice from death induced upon acute leptospirosis [9]. The antibody response at 15 days postinfection effectively controls leptospires, which are no longer found in the blood or in organs other than the kidney [ 5 , 13]. The nature of the humoral antibody response has been investigated and IgM and IgG were found [13]. In serum of sensitive mice, IgG was mostly of the IgG1 and IgG3 rather than of the IgG2a isotype, indicating a Th2-biased antibody response $[13,14]$, a feature usually observed to combat extracellular bacteria, consistent with the main localization of leptospires in blood or in the extracellular matrix.

Fibrosis is one clinical feature observed in human patients with leptospirosis. Usually, fibrosis results from a dysregulated repair mechanism occurring after a tissue injury or infection, driving fibroblasts to produce too many extracellular matrix components, such as collagen and $\alpha$-smooth muscle actin (sma, encoded by the acta- 2 gene) $[5,6]$. The pathological accumulation of these extracellular components results in the replacement of parenchymal tissue by connective tissues and may cause organ dysfunction. The tissue injury may lead to chronic inflammation and is often mediated by infiltrating macrophages. We and the Gomez group recently showed that the mild nephritis observed in Leptospirainfected C56BL6/J mice was associated with renal fibrosis, appearing as soon as 15 days postinfection and sustained thereafter $[10,12]$. Observation of renal collagen deposition by staining with Masson's trichrome or Picro Red Sirius revealed a mild focal fibrosis in mice $[10,12]$. Interestingly, the fibrosis was associated with the presence of live bacteria colonizing the kidney but not with their remaining antigens after an efficient antibiotic treatment [10]. Besides collagen, upregulation of fibronectin and acta- 2 mRNAs was measured in kidneys of mice 3 months postinfection [10], suggesting a wide dysregulation of extracellular matrix components. Inflammatory cytokines and chemokines, known to promote the fibrosis (IL-6, TNF, and RANTES), were highly upregulated at 15 days postinfection, and still upregulated, although to a lesser extent, 6 months postinfection [10]. Also, the Th2 IL-4 and IL-13 cytokines, known for their profibrotic role, have been shown to be upregulated 3 months postinfection in sensitive mice [12]. Other factors involved in resolution of fibrosis were also upregulated, such as the metalloprotease 2, also known as gelatinase [10], and IL-10 [12]. However, all mice are not prone to nephritis, and outbred OF1 mice infected with L. interrogans Icterohaemorrhagiae Verdun or $L$. borgpetersenii Ballum B3-13S strains did not exhibit nephritis or fibrosis 1 month postinfection, although they were still colonized with low levels of leptospires [7]. Interestingly, the extent of the fibrosis does not depend on the number of bacteria present in the kidney but rather on the infectious dose. Indeed, resistant or sensitive mice had comparable levels of fibrosis, although their renal colonizations were different [10], suggesting that the initial insult of entering the tubule is responsible for the fibrosis. Another atypical feature is the fact that the fibrosis does not depend on the adaptive immune response since transgenic mice devoid of $\mathrm{T}$ and/or B cells still exhibit fibrosis [10]. Of note, this showed that 
the Leptospira-induced fibrosis is not an autoimmune disease, as sometimes suggested. Leptospira-induced fibrosis is rather atypical since it does not rely on the upregulation of TGF- $\beta$, a classical profibrotic factor in mice $[10,12]$. This lack of TGF- $\beta$ upregulation has also been shown in hamsters surviving acute leptospirosis [15]. Even more surprising was the fact that mice devoid of important innate receptors involved in inflammation upon leptospiral recognition (see paragraph 2) were not less fibrotic. However, we and other groups showed that NO production had a dual role in the kidney disease upon leptospirosis. Indeed, the NO, produced by the iNOS, is a potent antimicrobial compound able to kill Leptospira, but at the same time, it is responsible for enhancing nephritis and fibrosis (see paragraph 2) $[10,16,17]$. The role of infiltrating macrophages producing NO [11] still remains to be tested in vivo to understand their contribution to the fibrosis.

Nevertheless, the intraperitoneal route of inoculation does not reflect the entrance of leptospires and the first phases of infection. Recently, a novel mouse model using sensitive $\mathrm{C} 3 \mathrm{H} / \mathrm{HeJ}$ mice infected through the conjunctival route of inoculation has shown that leptospires disseminate in blood, although with a delay compared to the intraperitoneal route, and provoke nephritis in the kidney, with glomerulus size reduction [18]. This novel model is interesting since it validates the peritoneal model. It also adds 1 model to identify virulence factors of leptospires. Indeed, some Leptospira mutants could still be virulent when injected in the peritoneal cavity but might be unable to enter the host.

\section{Host Innate Immune Determinants Important to Control the Disease or Harm the Kidney}

Mice are very resistant to leptospirosis, and intraperitoneal infection does not usually lead to death or to serious adverse outcome. However, some immune-compromised mice, and mice deficient in some innate immune receptors, have proved sensitive to acute leptospirosis and helped to understand the important factors driving protection or disease (Fig. 1, 2 , and for a comprehensive review and historical perspective, see $[8,19])$.

The humoral antibody response is a crucial factor determining the survival of mice after experimental leptospirosis. Therefore, B cells, producing Igs, are critical to control the acute phase of the infection and avoid death [9, 20-22]. A potent early response of IgM directed mainly against the O-antigen part of the LPS, and, later, IgG are efficient to protect mice from the severe disease $[9,23]$.

TLR4 is an innate immune receptor that recognizes the lipid A part of the bacterial LPS. The crucial role of TLR4 to control the leptospiral burden and avoid death induced by experimental leptospirosis has been shown in different studies, using either $\mathrm{C} 3 \mathrm{H} / \mathrm{HeJ}$ mice, harboring a natural mutation in TLR4, or ko mice for TLR4 $[9,24,25]$, both sensitive to the disease.

The IgM production depends on the signaling through TLR4 [9]. TLR4 has 2 adaptors: MyD88, the adaptor of surface TLRs, and TRIF, the adaptor of TLR4 when this receptor is located in the endosomal compartment. MyD88 and TRIF activation lead to NF- $\kappa \mathrm{B}$ and 


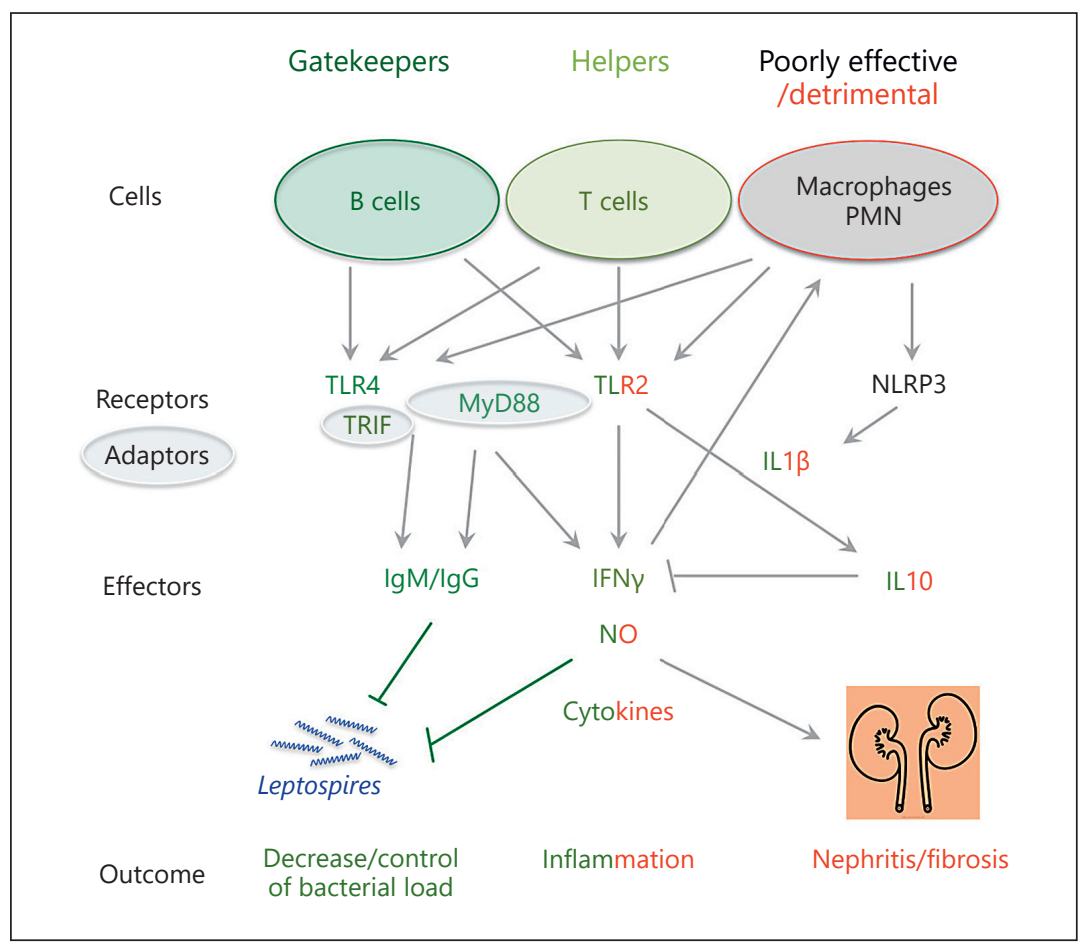

Fig. 2. Scheme depicting the host factors (cells, innate immune receptors/adaptors, and effectors) important to control (in green), to alleviate (light green), or to favor (in red) leptospirosis and kidney disease in mice. Factors with dual roles are depicted in double colors (green and red). The macrophages/ polymorphonuclear leukocytes are in black since their role is unclear, but they are encircled in red because they are recruited in the kidneys and may be involved in the IL-1 $\beta, \mathrm{IL}-10$, and NO productions, which are dual factors, not only favoring the control of the bacterial load but also enhancing the kidney disease. TLR, toll-like receptor; Ig, immunoglobulin; IL-1 $\beta$, interleukin-1 $\beta$; NLRP3, NOD-like receptor with a pyrin domain 3; IFN- $\gamma$, interferon $\gamma$; NO, nitric oxide; PMN, polymorphonuclear leukocytes.

MAP kinases activation, but in addition, TRIF stimulation leads to the activation of the IRF3 transcription factor. Altogether, these signaling pathways contribute to potent proinflammatory, antimicrobial, and type I interferon responses, aimed at alerting and recruiting phagocytes and fighting microbes [19].

We showed that the MyD88 pathway is crucial for mouse survival upon experimental leptospirosis, mainly because of its role in TLR 4 and TLR2 signaling [9]. IL- $1 \beta$ is 1 prominent proinflammatory cytokine orchestrating the inflammation. Its action on other cytokines activation is also dependent on MyD88, the adaptor of both the TLR and the IL-1 $\beta$ receptor. IL-1 $\beta$ production depends on the inflammasome, a platform of proteins, whose activation leads to the cleavage by caspase 1 of the pro-IL- $1 \beta$ to mature IL- $1 \beta$. The secretion of IL- $1 \beta$ is tightly regulated, depending on the production of 2 signals: first, a priming of the mRNA expression of the inflammasome components, and second, a danger signal activating the inflammasome receptor. We showed that the IL- $1 \beta$ secretion upon macrophage infection with L. interrogans is due to the activation of the cytosolic NOD-like 
receptor with a pyrin domain 3 inflammasome, through disturbance of the potassium flux [26]. It is known that the glycolipoprotein (GLP), a membrane toxin of pathogenic leptospires, downregulates the sodium potassium pump ( $\mathrm{Na} / \mathrm{K}$ ATPase) [27]. We showed that both LPS and GLP synergized to produce IL- $1 \beta$. The LPS and lipoproteins, through TLR2 and TLR4 activation, prime the mRNA expression of the inflammasome components, whereas the GLP activates the inflammasome [26]. We confirmed these results in vivo and showed that leptospires largely downregulate ionic renal transporters and are responsible for IL-1 $\beta$ production in mouse kidneys [26]. Other inflammatory cytokines and chemokines (among them TNF, IL-6, and RANTES) are also produced and participate in the kidney inflammation and nephritis $[9,10,26]$. However, surprisingly, this NOD-like receptor with a pyrin domain 3 inflammasome activation was not involved in the fibrosis.

Inflammatory cytokines are still highly expressed in MyD88ko mice infected with $L$. interrogans, suggesting that pathways other than TLRs are involved [9]. Recently, one inflammatory mechanism independent of MyD88 has been highlighted. Indeed, it has recently been suggested in mice that GLP activation of MAP kinases could participate in the detrimental lung's inflammation occurring upon leptospirosis [28].

Apart from these gatekeepers of the infection (Fig. 1), other factors are not crucial for the survival of infected mice but participate in the defense and protection of the kidney.

Along with TLR4, TLR2, recognizing the leptospiral LPS and lipoproteins, is involved in the protective IgG production [9]. The TRIF adaptor has also been recently found to play a slightly protective role in leptospirosis, as it is involved in the TLR4-driven IgM production [29]. Indeed, the IgM response was delayed in the TRIFko mice infected with the L. interrogans Copenhageni Fiocruz strain [29]. IFN- $\gamma$ is known for its ability to prime macrophages and boost their phagocytic functions. Its production upon L. interrogans infection relies on TLR4 or TLR2 signaling in the kidney [9]. Using ko mice and hematopoietic chimeras, we further showed that IFN- $\gamma$ is produced in the kidney from both $\mathrm{T}$ lymphocytes and parenchymal cells, conferring a unique double level of protection [9].

Using CD3ko mice, deficient for T cells, we showed that the nephritis was higher in the CD3ko mice compared to WT mice [9], suggesting a beneficial role of T cells. These results were in accordance with previous work showing that depletion of both CD8 and CD4 $\mathrm{T}$ cells resulted in increased interstitial nephritis in sensitive mice [25]. NO is an antimicrobial compound active against L. interrogans, as evidenced using mice devoid of the iNOS enzyme, which harbored slightly more bacteria in the kidneys $[10,16]$. Like IFN- $\gamma$, NO is produced in the kidney, in response to TLR2 and TLR4 signaling [9].

Some of these factors may also exert a detrimental role (Fig. 1). Indeed, NO production, like other reactive oxygen species, may be harmful for the host. It has been shown that NO participates in the nephritis and renal fibrosis [10, 17]. IL-10 is usually considered as a beneficial factor since it is a potent anti-inflammatory cytokine able to dampen the noxious inflammation. Recent studies showed that the kinetics and intensity of IL-10 production upon leptospirosis were different in sensitive hamsters compared to resistant mice $[30,31]$, suggesting a protective role of early IL-10 production. However, a deleterious role of IL-10 in the kidney has been recently shown in mice. Strikingly, IL-10ko mice 
or mice depleted of IL-10 using neutralizing antibodies were shown to be devoid of any renal colonization $[30,32]$. This effect has been linked to the presence of IFN- $\gamma$ in the kidney, which would be efficient to clear the bacteria [32]. In WT mice, IL-10 would counteract IFN- $\gamma$, enabling the leptospires to colonize the kidney. Leptospires are covered in lipoproteins and are potent TLR2 agonists, as demonstrated for the major LipL32 lipoprotein $[33,34]$. An inflammatory role of LipL32 has been recently shown to induce nephritis in the zebrafish model [35]. However, no major role of TLR2 has been demonstrated since TLR2ko mice survive the infection, and LipL32 leptospire mutants are still virulent in mice, hamsters, and rats [8]. Consistently, the fibrosis levels were not modified in TLR2ko mice, although they harbored a little more bacterium in their kidneys than WT mice [10]. One hypothesis that could explain these puzzling results has been raised by recent data, showing posttranslational modifications of LipL32 in leptospires retrieved from rat urine, which may impair murine TLR2 recognition [36].

Recently, it has been shown that IL-10 was decreased in TLR2ko mice infected with leptospires [37], suggesting that TLR2 activation leads to IL-10 production and would thus be crucial to favor the renal colonization by leptospires. Therefore, TLR2 would exert a dual role (Fig. 2). On the one hand, TLR2 plays a protective role, being involved in the production of protective antibodies and cytokines and/or helping the host to survive the acute phase of leptospirosis when activated by a synthetic agonist [37], but, on the other hand, it sustains the leptospires' ability to escape the immune response and survive, hidden in the kidney.

\section{Conclusion}

Leptospirosis is a biphasic disease, and the mouse model is appropriate to study the acute forms associated with nephritis as well as chronic renal colonization associated with fibrosis. Most of the time, leptospires are stealthy and discrete pathogens, which seldom kill their hosts. The renal disease is usually limited or even unnoticed but may still weaken the renal functions. Therefore, chronically infected mice could provide a robust model to study the consequences of renal leptospirosis that predispose to serious kidney diseases, such as chronic kidney disease in humans [3].

The recently highlighted role of TLR2 stimulation by leptospires, activating IL-10 production and antagonizing IFN- $\gamma$ to allow renal colonization, exemplifies the leptospires' ability to avoid or subvert the immune response for their own benefit. We are only at the infancy of understanding the complexity in kidney disease due to pathogenic Leptospira and the positive or detrimental role of pattern recognition receptors. Although some pattern recognition receptors such as TLR4 and NOD1 display some host species specificities and induce differential recognition of leptospires between mice and human [38, 39], availability of mouse models, including transgenic and humanized mice, will be instrumental to boost further research and decipher the pathophysiology of renal leptospirosis and the mechanisms of pathogenic leptospires to escape the innate immune defenses. 


\section{Acknowledgements}

We acknowledge Frédérique Vernel-Pauillac for critical reading, Richard Wheeler for English editing, and Delphine Bonhomme for help with the figures.

\section{References}

1 Ko AI, Goarant C, Picardeau M: Leptospira: the dawn of the molecular genetics era for an emerging zoonotic pathogen. Nat Rev Microbiol 2009;7:736-747.

2 Ganoza CA, Matthias MA, Saito M, Cespedes M, Gotuzzo E, Vinetz JM: Asymptomatic renal colonization of humans in the peruvian Amazon by Leptospira. PLoS Negl Trop Dis 2010;4:e612.

3 Yang CW: Leptospirosis renal disease: emerging culprit of chronic kidney disease unknown etiology. Nephron 2018;138:129-136.

4 Herath NJ, Kularatne SA, Weerakoon KG, Wazil A, Subasinghe N, Ratnatunga NV: Long term outcome of acute kidney injury due to leptospirosis? A longitudinal study in Sri Lanka. BMC Res Notes 2014;7:398.

5 Ratet G, Veyrier FJ, Fanton d'Andon M, Kammerscheit X, Nicola MA, Picardeau M, Boneca IG, Werts C: Live imaging of bioluminescent Leptospira interrogans in mice reveals renal colonization as a stealth escape from the blood defenses and antibiotics. PLoS Negl Trop Dis 2014; 8:e3359.

6 Athanazio DA, Silva EF, Santos CS, Rocha GM, VannierSantos MA, McBride AJ, Ko AI, Reis MG: Rattus norvegicus as a model for persistent renal colonization by pathogenic Leptospira interrogans. Acta Trop 2008; 105 176-180.

7 Matsui M, Roche L, Geroult S, Soupe-Gilbert ME, Monchy D, Huerre M, Goarant C: Cytokine and chemokine expression in kidneys during chronic leptospirosis in reservoir and susceptible animal models. PLoS One 2016; 11:e0156084.

8 Gomes-Solecki M, Santecchia I, Werts C: Animal models of leptospirosis: of mice and hamsters. Front Immunol 2017;8:58.

9 Chassin C, Picardeau M, Goujon JM, Bourhy P, Quellard N, Darche S, Badell E, d'Andon MF, Winter N, LacroixLamande S, Buzoni-Gatel D, Vandewalle A, Werts C: TLR4- and TLR2-mediated B cell responses control the clearance of the bacterial pathogen, Leptospira interrogans. J Immunol 2009;183:2669-2677.

10 Fanton d'Andon M, Quellard N, Fernandez B, Ratet G, Lacroix-Lamande S, Vandewalle A, Boneca IG, Goujon JM, Werts C: Leptospira Interrogans induces fibrosis in the mouse kidney through Inos-dependent, TLR- and NLR-independent signaling pathways. PLoS Negl Trop Dis 2014;8:e2664.

11 Chen X, Li SJ, Ojcius DM, Sun AH, Hu WL, Lin X, Yan J: Mononuclear-macrophages but not neutrophils act as major infiltrating anti-leptospiral phagocytes during leptospirosis. PLoS One 2017;12:e0181014.
12 Ferrer MF, Scharrig E, Alberdi L, Cedola M, Pretre G, Drut R, Song WC, Gomez RM: Decay-accelerating factor 1 deficiency exacerbates leptospiral-induced murine chronic nephritis and renal fibrosis. PLoS One 2014; 9:e102860.

13 Richer L, Potula HH, Melo R, Vieira A, Gomes-Solecki M: Mouse model for sublethal Leptospira interrogans infection. Infect Immun 2015;83:4693-4700.

14 Potula HH, Richer L, Werts C, Gomes-Solecki M: Pretreatment with Lactobacillus plantarum prevents severe pathogenesis in mice infected with Leptospira interrogans and may be associated with recruitment of myeloid cells. PLoS Negl Trop Dis 2017;11:e0005870.

15 Matsui M, Roche L, Soupe-Gilbert ME, Roudier M, Moniquet V, Goarant C: Experimental hamster infection with a strain of Leptospira borgpetersenii Ballum Isolated from a Reservoir Mouse in New Caledonia. Am J Trop Med Hyg 2015;92:982-985.

16 Pretre G, Olivera N, Cedola M, Haase S, Alberdi L, Brihuega B, Gomez RM: Role of inducible nitric oxide synthase in the pathogenesis of experimental leptospirosis. Microb Pathog 2011;51:203-208.

17 Bandeira M, Santos CS, de Azevedo EC, Soares LM, Macedo JO, Marchi S, da Silva CL, Chagas-Junior AD, McBride AJ, McBride FW, Reis MG, Athanazio DA: Attenuated nephritis in inducible nitric oxide synthase knockout C57BL/6 mice and pulmonary hemorrhage in CB17 SCID and recombination activating gene 1 knockout C57BL/6 mice infected with Leptospira interrogans. Infect Immun 2011;79:2936-2940.

18 Sullivan JP, Nair N, Potula HH, Gomes-Solecki M: Eyedrop inoculation causes sublethal Leptospirosis in mice. Infect Immun 2017;85:pii:e01050-16.

19 Werts C: Interaction of Leptospira with the Innate Immune System. Curr Top Microbiol Immunol 2018;415: 163-187.

20 Thiermann AB: Effect of cyclophosphamide treatment on clinical and serologic response of rats to infection with Leptospira interrogans serovar icterohaemorrhagiae. Am J Vet Res 1980;41:1655-1658.

21 Adler B, Faine S, Muller HK, Green DE: Maturation of humoral immune response determines the susceptibility of guinea-pigs to leptospirosis. Pathology 1980;12:529538.

22 Adler B, Faine S: Susceptibility of mice treated with cyclophosphamide to lethal infection with Leptospira interrogans Serovar pomona. Infect Immun 1976;14:703-708.

23 Adler B: Vaccines against leptospirosis. Curr Top Microbiol Immunol 2015;387:251-272. 
24 Viriyakosol S, Matthias MA, Swancutt MA, Kirkland TN, Vinetz JM: Toll-like receptor 4 protects against lethal Leptospira interrogans serovar icterohaemorrhagiae infection and contributes to in vivo control of leptospiral burden. Infect Immun 2006;74:887-895.

25 Pereira MM, Andrade J, Marchevsky RS, Ribeiro dos Santos R: Morphological characterization of lung and kidney lesions in $\mathrm{C} 3 \mathrm{H} / \mathrm{HeJ}$ mice infected with Leptospira interrogans serovar icterohaemorrhagiae: defect of $\mathrm{CD} 4+$ and CD8+ T-cells are prognosticators of the disease progression. Exp Toxicol Pathol 1998;50:191-198.

26 Lacroix-Lamande S, d'Andon MF, Michel E, Ratet G, Philpott DJ, Girardin SE, Boneca IG, Vandewalle A, Werts C: Downregulation of the Na/K-ATPase pump by leptospiral glycolipoprotein activates the NLRP3 inflammasome. J Immunol 2012;188:2805-2814.

27 Younes-Ibrahim M, Burth P, Faria MV, Buffin-Meyer B, Marsy S, Barlet-Bas C, Cheval L, Doucet A: Inhibition of $\mathrm{Na}, \mathrm{K}-\mathrm{ATP}$ ase by an endotoxin extracted from Leptospira interrogans: a possible mechanism for the physiopathology of leptospirosis. C R Acad Sci III 1995;318:619-625.

28 Goncalves-de-Albuquerque CF, Burth P, Silva AR, de Moraes IM, Oliveira FM, Santelli RE, Freire AS, de Lima GS, da Silva ED, da Silva CI, Morandi V, Bozza PT, Younes-Ibrahim M, de Castro Faria Neto HC, de Castro Faria MV: Murine lung injury caused by Leptospira interrogans glycolipoprotein, a specific $\mathrm{Na} / \mathrm{K}-\mathrm{ATPa} e$ inhibitor. Respir Res 2014;15:93.

29 Jayaraman PA, Devlin AA, Miller JC, Scholle F: The adaptor molecule Trif contributes to murine host defense during Leptospiral infection. Immunobiology 2016;221: 964-974.

30 Matsui M, Roche L, Soupe-Gilbert ME, Hasan M, Monchy D, Goarant C: High level of IL-10 expression in the blood of animal models possibly relates to resistance against leptospirosis. Cytokine 2017;96:144-151.

31 Matsui M, Rouleau V, Bruyere-Ostells L, Goarant C: Gene expression profiles of immune mediators and histopathological findings in animal models of leptospirosis: comparison between susceptible hamsters and resistant mice. Infect Immun 2011;79:4480-4492.
32 Devlin AA, Halvorsen PJ, Miller JC, Laster SM: Il-10 deficient mice express IFN-gamma mRNA and clear Leptospira interrogans from their kidneys more rapidly than normal C57BL/6 mice. Immunobiology 2017;222:768777.

33 Werts C, Tapping RI, Mathison JC, Chuang TH, Kravchenko V, Saint Girons I, Haake DA, Godowski PJ, Hayashi F, Ozinsky A, Underhill DM, Kirschning CJ, Wagner H, Aderem A, Tobias PS, Ulevitch RJ: Leptospiral lipopolysaccharide activates cells through a TLR2-dependent mechanism. Nat Immunol 2001;2:346-352.

34 Hsu SH, Lo YY, Tung JY, Ko YC, Sun YJ, Hung CC, Yang CW, Tseng FG, Fu CC, Pan RL: Leptospiral outer membrane lipoprotein LipL32 binding on toll-like receptor 2 of renal cells as determined with an atomic force microscope. Biochemistry 2010;49:5408-5417.

35 Chang MY, Cheng YC, Hsu SH, Ma TL, Chou LF, Hsu HH, Tian YC, Chen YC, Sun YJ, Hung CC, Pan RL, Yang CW: Leptospiral outer membrane protein LipL32 induces inflammation and kidney injury in zebrafish larvae. Sci Rep 2016;6:27838.

36 Witchell TD, Eshghi A, Nally JE, Hof R, Boulanger MJ, Wunder EA, Jr., Ko AI, Haake DA, Cameron CE: Posttranslational modification of LipL32 during Leptospira interrogans infection. PLoS Negl Trop Dis 2014;8:e3280.

37 Zhang W, Zhang N, Xie X, Guo J, Jin X, Xue F, Ding Z, Cao Y: Toll-like receptor 2 agonist Pam3CSK4 alleviates the pathology of Leptospirosis in hamster. Infect Immun 2016;84:3350-3357.

38 Nahori MA, Fournie-Amazouz E, Que-Gewirth NS, Balloy V, Chignard M, Raetz CR, Saint Girons I, Werts C: Differential TLR recognition of leptospiral lipid A and lipopolysaccharide in murine and human cells. J Immunol 2005; 175:6022-6031.

39 Ratet G, Santecchia I, Fanton d'Andon M, Vernel-Pauillac F, Wheeler R, Lenormand P, Fischer F, Lechat P, Haake DA, Picardeau M, Boneca IG, Werts C: LipL21 lipoprotein binding to peptidoglycan enables Leptospira interrogans to escape NOD1 and NOD2 recognition. PLoS Pathog 2017;13:e1006725. 